\title{
Seasonality, barrage (Farakka) regulated hydrology and flood scenarios of the Ganga River: a study based on MNDWI and simple Gumbel model
}

\author{
Raghunath Pal ${ }^{1} \cdot$ Padmini Pani $^{1}$
}

Received: 17 March 2016/ Accepted: 18 March 2016/Published online: 29 March 2016

(C) Springer International Publishing Switzerland 2016

\begin{abstract}
The hydrology of the Ganga River is mainly characterized by high monsoon rainfall and seasonal variability in discharge flow. The study is focuses on both the up and down-streams of Farakka barrage. It has been executed with the help of Modified Normalized Difference Water Index using Landsat satellite images (2014), satellite based discharge data and Gumbel's flood frequency analysis. The study aims to analyse the impacts of seasonality, floods and the construction of Farakka barrage on hydrology of the Ganga River. The study reflects higher values in annual maximum discharge near Jangipur which is probably a resultant of the extra water release from the barrage during the strong monsoon flow. The reduction of $\mathrm{R}^{2}$ value during the non-monsoon season in comparison to the monsoon season is because of the control of Farakka barrage on the discharge release. The monsoon season discharge is influenced more by the barrage than the monsoon season runoff. The magnitude of the floods in terms of their maximum daily discharge and flood volume is higher in the up-stream (Rajmahal station) than in the downstream of Farakka barrage. Furthermore, annual minor floods and floods with 10 years recurrence interval play a significant role in the river hydrology and morphology.
\end{abstract}

Keywords Landsat images - Seasonality - MNDWI · Flood frequency analysis · Gumbel model · Ganga River

Raghunath Pal

raghunath.geo17@gmail.com

1 Centre for the Study of Regional Development, School of Social Science, Jawaharlal Nehru University, New Delhi 110067, India

\section{Introduction}

The Ganga River, India's national river, drains $2525 \mathrm{~km}$ long distance and the basin covers an area of about 10 , $60,000 \mathrm{~km}^{2}$ which is $26.2 \%$ of the total surface area of India (Singh 1971, 2007). It begets as Bhagirathi from the Gangotri Glacier at Gaumukh at an elevation of $3800 \mathrm{~m}$. The river enters the alluvial plain at Haridwar about $310 \mathrm{~km}$ from its source and it enters the delta after passing the Rajmahal trap. At Farakka, the river splits into two distributaries i.e. the Padma and the Bhagirathi-Hughly. The Padma, the main distributary of Ganga enters Bangladesh and meets the Brahmaputra at Rajbari (Singh 2007). The vast Ganga River basin is a museum of hydrology, geomorphology and archeology. The hydrology of the Ganga River is largely controlled by monsoon season rainfall and seasonality over the centuries (Singh 1971, 2007; Rudra 2010a, b). The river carries high discharge throughout the monsoon season but remains with low discharge during the non-monsoon period. Flood is another very common hydrological event of the river and has a key role in shaping the river hydrology along with the morphological structure (Mirza 1997; Singh 2007; Singh et al. 2007). However, the hydrological scenario of the river was modified abruptly particularly in the down-stream of the barrage after the commission of Farakka barrage in 1975. Since then the distribution of discharge of the Ganga River has become both a morphological as well as a political issue between India and Bangladesh (Mirza 1997; Rudra 2010a, b). The issue of enclave distribution is also a major problem between these two countries because the river is highly dynamic in terms of its lateral shifting, formation of new bars on the channel floor which have been triggered by recent hydrological changes. Furthermore, human habitats and riverine environment etc. are also being affected 
significantly by seasonality, floods and Farakka barrage in the particular reach.

Landsat archives, satellite based discharge data and hydrological models give the opportunity to analyse the modification and the consequences of the hydrological condition of rivers as well as morphological status caused by seasonality and anthropogenic factors (Yue et al. 1999; Xu 2006; Gupta et al. 2013, 2014). The study mainly focuses on the up and down-stream of Farakka barrage and has been executed with the help of Landsat satellite images, satellite based discharge data and Gumbel's flood frequency analysis etc. The objectives of the study are twofold, first is the study tries to understand the changing hydrology of the river caused by seasonality and Farakka barrage and the second is to analyse the flood scenario of the river and the impacts of the barrage to the flood events with respect to Rajmahal and Jangipur stations as the barrage lies between these two stations.

\section{Study area}

The study reach of the Ganga River extends from the north of Rajmahal in Jharkhand to Jangipur in West Bengal. The course of the river is about $118 \mathrm{~km}$ long in the reach. Farakka barrage was constructed at the apex of the GangaBrahmaputra delta between Rajmahal and Jangipur and a feeder canal $(\sim 40 \mathrm{~km})$ was also constructed on the right bank of the Ganga to rejuvenate and deliver discharge to the Bhagirathi-Hughly River (Fig. 1). The BhagirathiHughly River is the prime distributary and it bifurcated from the mighty Ganga at Mithipur before the construction of the barrage (Rudra 2010a, b). However, presently, the river is directly connected to the distributary BhagirathiHughly with the feeder canal. Since the construction of the barrage the surface morphology of the floodplain of the Ganga River has changed rapidly and particularly in the study reach there is no such significant similarity between the pre and post barrage period surface morphology of the river. The barrage plays an immense role in the hydrology and planform morphology of the river particularly in the immediate up and downstream (Rudra 2010a, b). The distance from Farakka to Rajmahal along the channel is about $48 \mathrm{~km}$ and it is about $70 \mathrm{~km}$ from Farakka to Jangipur. These two stations have been selected to understand and justify the impact of seasonality, flood and Farakka barrage in the up-stream and down-stream hydrology as only these two stations data is available.

Seasonality largely controls the Ganga River. The annual hydrograph of most of the middle and lower reach stations indicate that the flow during monsoon season is very high including Farakka (Singh 2007). The hydrographs at different reaches include several peaks of high discharge that indicate flow flexibility of the river (Singh et al. 2007). The Ganga River has a mixed source of discharge. The primary sources of discharge for the river are precipitation, sub-surface flows and the melt water from the glaciers. Among these, the glaciers have limited
Fig. 1 Location map of the study reach of the River Ganga

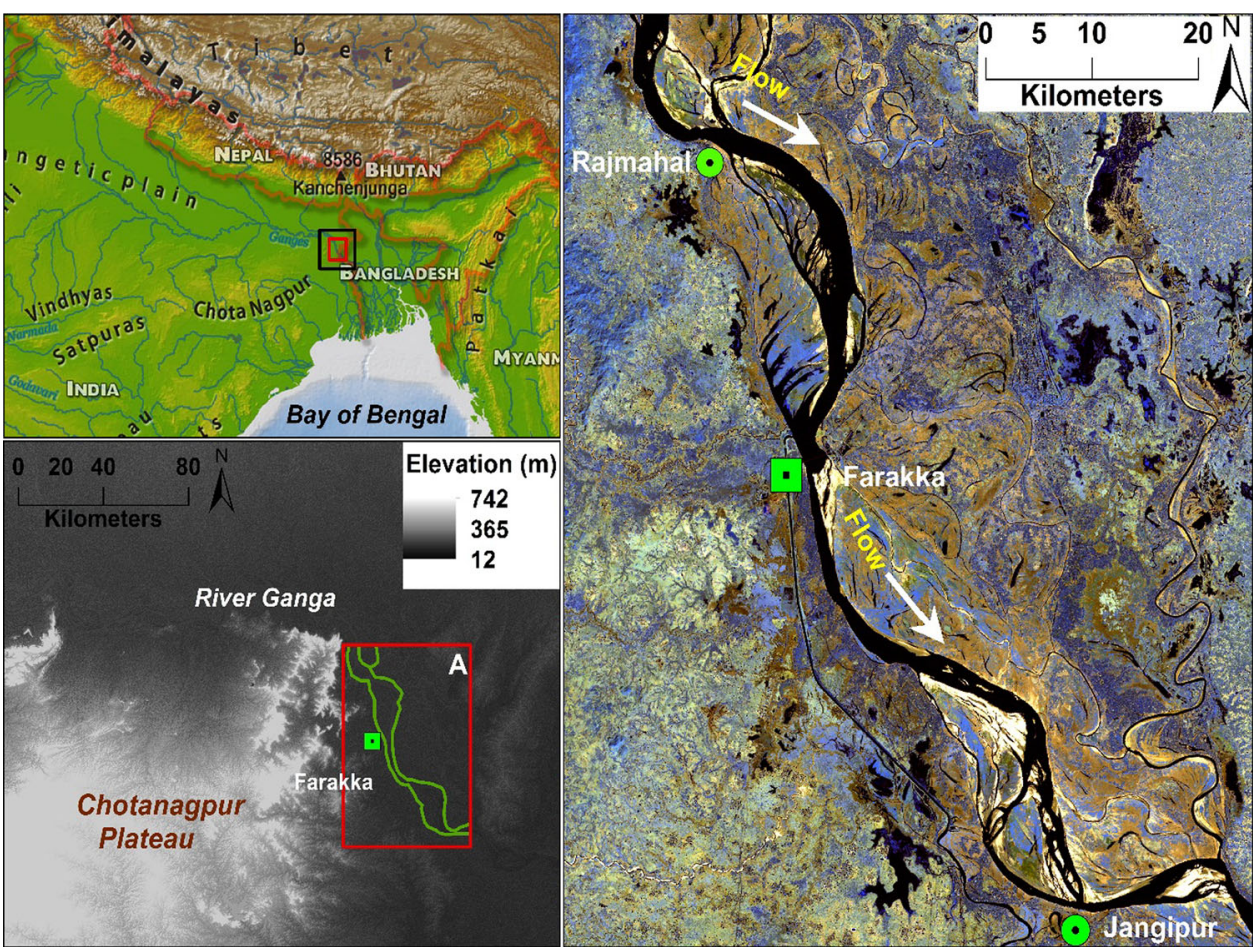


Table 1 Seasonal variability of discharge and avg. annual discharge at Farakka (1949-1973)

\begin{tabular}{llll}
\hline Years & $\begin{array}{l}\text { Monsoon (June-Nov.) } \\
\text { discharge }\left(\mathrm{m}^{3} / \mathrm{s}\right)\end{array}$ & $\begin{array}{l}\text { Non-monsoon }(\text { Dec.-June }) \\
\text { discharge }\left(\mathrm{m}^{3} / \mathrm{s}\right)\end{array}$ & $\begin{array}{c}\text { Avg. annual discharge }\left(\mathrm{m}^{3} / \mathrm{s}\right) \\
1949-1954\end{array}$ \\
\hline $25,298.30$ & 2898.13 & $12,264.62$ \\
$1955-1960$ & $27,994.60$ & 2871.07 & $13,370.83$ \\
$1965-1970$ & $21,105.57$ & 2507.90 & $10,256.50$ \\
$1971-1973$ & $26,052.87$ & 2614.10 & $12,473.77$ \\
\hline
\end{tabular}

Data source http://www.sage.wisc.edu/riverdata

contribution to the total discharge (Singh 1971). Table 1 exhibits seasonal variability of discharge and average annual discharge in the period of 1949-1954, 1955-1960, 1966-1970 and 1971-1973 at Farakka. Moreover, annual flooding is one of the major characteristics of river Ganga and its tributaries. The Ganga River carries a high volume of sediment load in terms of suspended load and bedload. The Ganga-Brahmaputra River system produces about $1.7 \times 10^{9} \mathrm{t}$ of sediment load annually (Singh 2007). The suspended sediment concentration along the river at different stations are $105-339 \mathrm{mgl}^{-1}$ at Sultanganj, $78-119 \mathrm{mgl}^{-1}$ at Bhagalpur and 729 million tons at Farakka (Singh 2007). The river Ganga unloads a huge amount of bedload onto the Ganga-Brahmaputra Delta and the estimated value is about $600 \times 10^{6}-2500 \times 10^{6} \mathrm{t} \mathrm{year}^{-1}$ (Singh 2007).

\section{Methodology}

\section{Data used}

For this study satellite images have been used to understand both the effects of seasonality and Farakka barrage. In order to explain the effect of seasonality the images of two different seasons of Landsat 5 TM (2014) have been incorporated here. The image of 21 st October has been considered as a representative of monsoon season whereas the image of 13th April represents of the non-monsoon season. On the other hand to examine the impact of the barrage construction on the hydrology of the reach the images of upstream and downstream of the barrage have been incorporated here. Furthermore, for the understanding of the impact of seasonality and the barrage, mean annual and total maximum discharge and runoff data of the same two stations i.e., near Rajmahal (GFDS ${ }^{1}$ Site No. 51) (upstream) and near Jangipur (GFDS Site No. 193) (downstream) for the last 17 years (1998-2014) have been used (http://floodobservatory.color ado.edu/SiteDisplays.htm). In order to analyse the flood scenario and its influence on the study reach daily maximum

${ }^{1}$ GFDS-Global Flood Detection System. discharge and discharge volume data of the two stations (i.e., Rajmahal and Jangipur) have been considered. In this study, pre and post barrage data (peak discharge and volume) of Farakka could not be incorporated due to its unavailability and hence, experimental satellite-based river discharge data has been used (http://floodobservatory.colorado.edu/Site Displays.htm).

\section{GIS analysis}

In order to analyse the impact of seasonality and construction of the barrage it is necessary to extract open water signatures from the other signatures of an image. There are two different ways to extract water covered area from a multi-band image. The first is through the identification of water covered areas and shape files creation of that particular signature and then the extraction of the signatures. The second is a band ratio method where two different bands of an image are used (Xu 2006). The second method known as MNDWI (Modified Normalized Difference Water Index) has been applied for the image processing of the present study. The method was developed by Xu (2006) and was the modified form of NDWI method (Normalized Difference Water Index) that was coined by Xu (2006). The method can be written as follows in case of Landsat 5 TM:

$$
\begin{aligned}
\text { MNDWI } & =\frac{\text { Band } 2-\text { Band } 5}{\text { Band } 2+\text { Band } 5} \\
& =\frac{\text { Green }- \text { MIR }(\text { Mid }- \text { infrared })}{\text { Green }+ \text { MIR }(\text { Mid }- \text { infrared })}
\end{aligned}
$$

In this study, the images of monsoon and non-monsoon have been represented after the MNDWI analysis. The method helps to understand the changes of the river water surface coverage which are resultant of seasonality and the construction of Farakka barrage.

\section{Statistical analysis}

Discharge and runoff data of each year have been classified as monsoon and non-monsoon period on the basis of the amount of discharge flow. The monsoon period is 
considered from July to November for high discharge and the non-monsoon period extends from December to June for relatively low discharge ( $\mathrm{Pal} 2015)$. Then each dataset of discharge and runoff of Rajmahal and Jangipur stations has been analysed and compared with one another with the help of simple regression analysis.

\section{Flood model}

The Ganga River is a tropical river and carries an enormous amount of discharge from different sources. The entire river basin is under the monsoon climatic region which indicates the considerable impact of seasonal rainfall variability on the river discharge. Previous studies suggest that the Ganga River experiences yearly flood of different magnitudes (Singh 1987, 2004, 2007; Sinha and Friend 1994; Singh et al. 2007). Hence, in order to understand the role of floods in changing the fluvial structure and its vibrant hydrology, the analysis of the flooding scenario is essential. In the study reach yearly and decadal flood events have a significant role in the understanding of the evolution of the adjoining floodplains. The standard method for the identification of annual and decadal flood events is flood frequency analysis. Among the various methods of flood frequency analysis, Gumbel method is very popular and common. The method is known as Gumbel distribution. It was founded in 1941 and after that it became one of the most commonly used probability distribution to analyse and predict the distribution of extreme values of various climatic and hydrologic parameters i.e. flood volume, flood peak, flood duration and maximum rainfalls etc.

In Gumbel method (Yue et al. 1999; Raghunath 2006; Subramanya 2013) the occurrence probability of an event equal to or larger than a value $x_{0}$ can be written as

$F\left(X \geq x_{0}\right)=1-e^{-e^{-\beta}}$

where, $\beta$ is a dimensionless variable which can be defined by

$$
\begin{aligned}
& \beta=\alpha(x-\omega) \\
& \omega=\bar{x}-0.45005 \sigma_{x} \\
& \alpha=\frac{1.2825}{\sigma_{x}}
\end{aligned}
$$

From above three $\beta$ can be formulated as
Fig. 2 Mean annual discharge $\left(\mathrm{m}^{3} / \mathrm{s}\right)$ a and annual maximum discharge $\left(\mathrm{m}^{3} / \mathrm{s}\right)$ b of two stations: near Rajmahal and Jangipur. Data is satellite based passive microwave radiometry
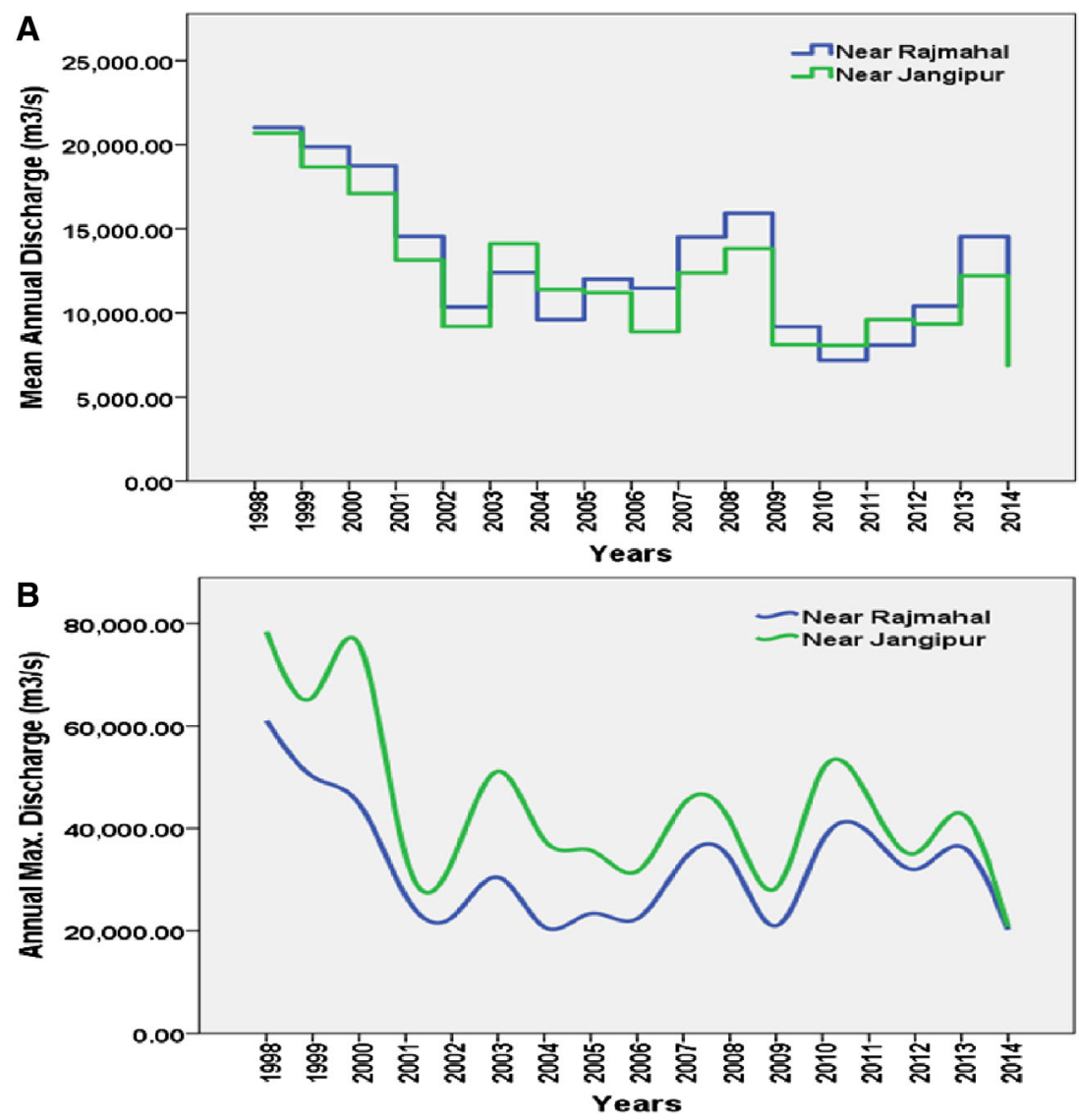
$\beta=\frac{1.2825(x-\bar{x})}{\sigma_{x}}+0.577$

where, $\bar{x}=$ mean and $\sigma_{x}=$ standard deviation of the variable $X$. Here, $X$ is a value for a given $F$ that is necessary and can be transposed as

$\beta_{F}=-\ln \{-\ln (1-F)\}$

Here, the return period $(\mathrm{T})$ is required to calculate reduced variate and it can be formulated as

$T=\frac{1}{F}=\frac{N+1}{m}$

where, $F$ is the probability of each event, $N$ is the number of observations and $\mathrm{m}$ is the rank of an individual event. For a given $T$, the reduced variate $\left(\beta_{T}\right)$ can be derived as

$\beta_{T}=-\left[\ln \cdot \ln \frac{T}{T-1}\right]$

It can also be written as

$\beta_{T}=-\left[0.834+2.303 \log \log \frac{T}{T-1}\right]$

Now, the value of the variable $\mathrm{X}$ with a return period (recurrence interval) $\mathrm{T}$ can be formulated as
$x_{T}=\bar{x}+K \sigma_{x}$

where, $\quad K=\frac{\left(\beta_{T}-\bar{\beta}_{n}\right)}{S_{n}}$

or $K=\frac{\left(\beta_{T}-0.577\right)}{1.2825}$

where, $K$ is constant, $\bar{\beta}_{n}$ is reduced mean, a function of sample size $N$ and its value is 0.577 for $N \rightarrow \infty$ and $S_{n}$ is the reduced standard deviation, a function of sample size $N$ and its value is 1.2825 for $N \rightarrow \infty$.

The limitation of the use of this flood model in this study is that the model demands at least 30 samples for the flood frequency analysis but the study incorporates 17 years data because of the unavailability of 30 years or more discharge data. However, a flood is a multivariate event and it includes not only flood peak but also flood volume and flood duration (Yue et al. 1999). Among these variables flood peak or peak discharge and flood volume or discharge volume have been incorporated in this study while flood duration was not taken into consideration due to the lack of data. Furthermore, daily maximum discharge data has been used in the study as a substitute of peak discharge as the peak discharge data was unavailable.

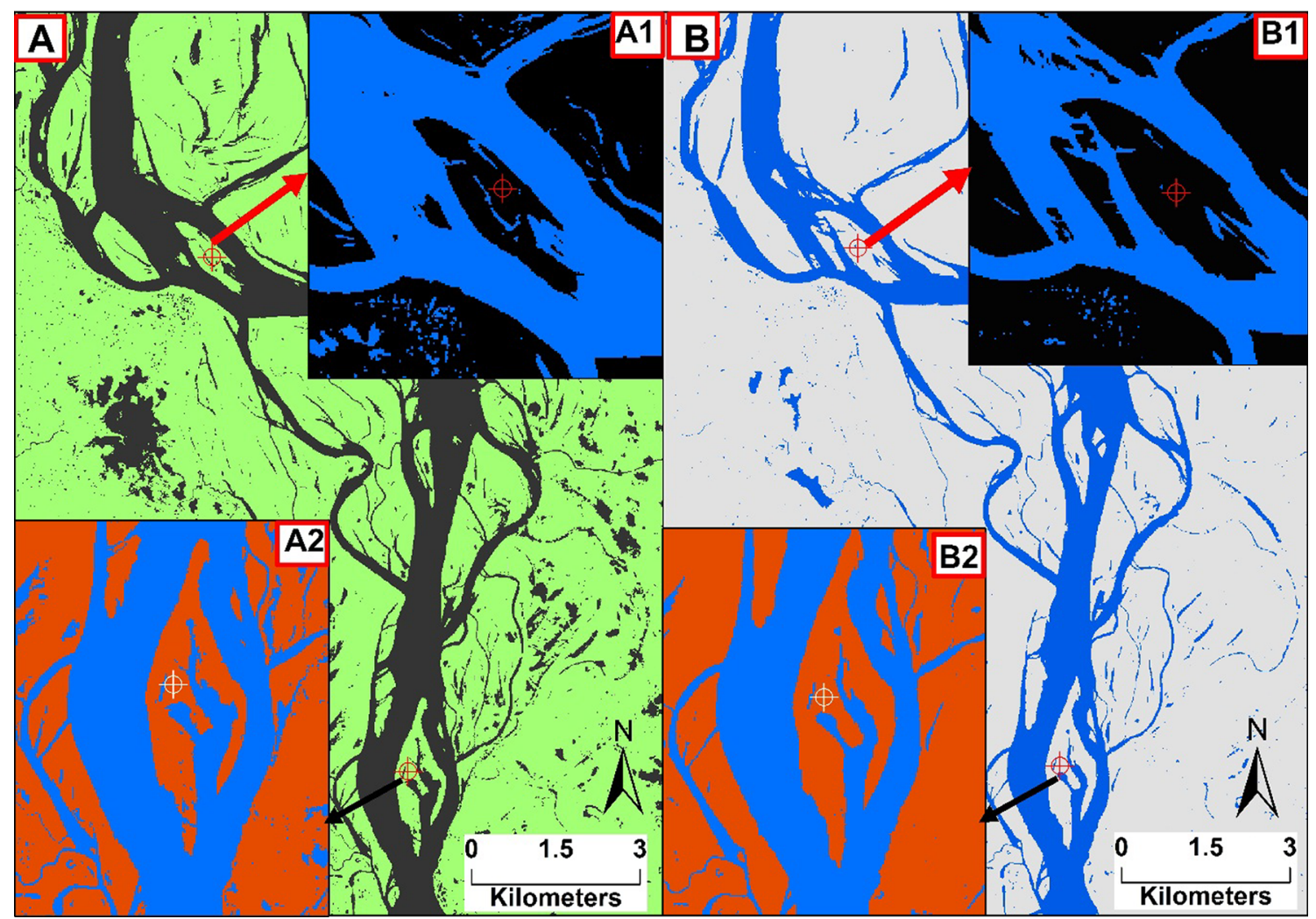

Fig. 3 MNDWI images of the up-stream of Farakka barrage. 'A' is for monsoon season and " $\mathrm{B}$ ' is for non-monsoon season. $A 1$ and $A 2$ indicate the location of bars for monsoon season, and $B 1$ and $B 2$ indicate the location of bars for non-monsoon season 


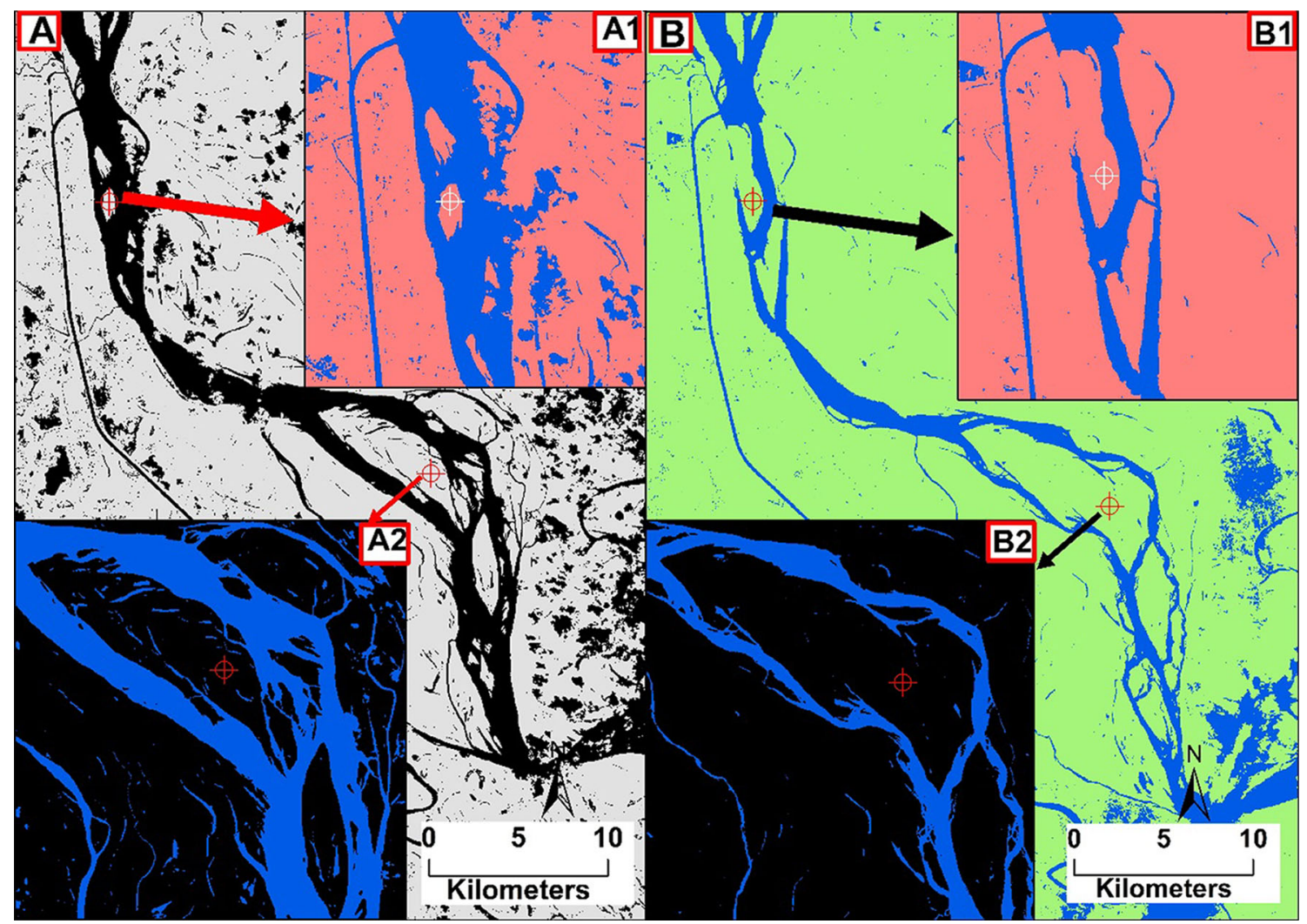

Fig. 4 MNDWI images of the down-stream of Farakka barrage. 'A' is for monsoon season and "B' is for non-monsoon season. $A 1$ and $A 2$ indicate the location of bars for monsoon season, and $B 1$ and $B 2$ indicate the location of bars for non-monsoon season

Fig. 5 Relationships of seasonal discharge and runoff between Rajmahal and Jangipur in the period of 1998-2014. 'A' indicates the relation of mean monsoon (July-Nov.) discharge $\left(\mathrm{m}^{3} / \mathrm{s}\right)$ between the two stations, ' $\mathrm{B}$ ' indicates mean nonmonsoon (Dec.-June) discharge $\left(\mathrm{m}^{3} / \mathrm{s}\right)$, ' $\mathrm{C}$ ' indicates mean monsoon (July-Nov.) runoff $(\mathrm{mm})$ and ' $\mathrm{D}$ ' indicates mean non-monsoon (Dec.-June) runoff $(\mathrm{mm})$
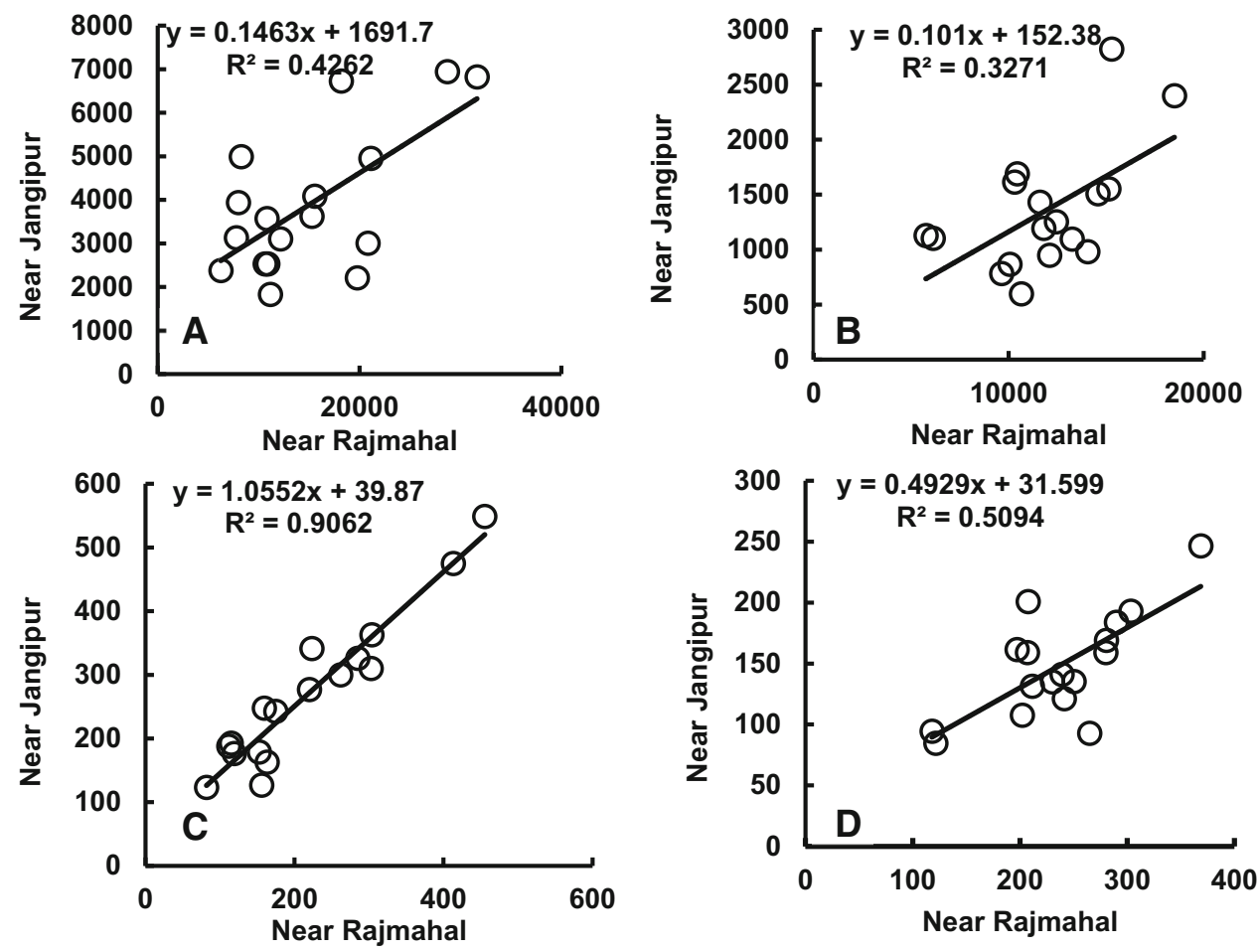


\section{Results and discussions}

\section{Hydrology of the Ganga River in the reach}

It has been mentioned in methodology that the changes in the channel hydrology after Farakka barrage construction has been established considering the discharge and runoff data of Farakka barrage's upstream (near Rajmahal) and downstream (near Jangipur) stations during the period of 1998-2014 (data is satellite based passive microwave radiometry). Figure 2 displays the distribution and variability of mean annual discharge $\left(\mathrm{m}^{3} / \mathrm{s}\right)$ and annual maximum discharge $\left(\mathrm{m}^{3} / \mathrm{s}\right)$ of two stations viz. Rajmahal and Jangipur. Figure 2a indicates high mean annual discharge for the years 1998, 1999, 2000, 2001, 2007, 2008 and 2013 near Rajmahal (discharge ranges from 13,000-21,000 m 3 / s) and low $\left(7000-10,000 \mathrm{~m}^{3} / \mathrm{s}\right)$ mean annual discharge for the years 2002, 2004, 2009, 2010 and 2011. The Jangipur station experienced high mean annual discharge in the years of 1998, 1999, 2000, 2001, 2003, 2007, 2008 and $2013\left(12,500-20,000 \mathrm{~m}^{3} / \mathrm{s}\right)$ and it is low in the years 2002 , 2006, 2009, 2010 and $2012\left(5500-8000 \mathrm{~m}^{3} / \mathrm{s}\right)$. Here, it is obvious that the high and the low mean annual discharge is greater near Rajmahal than in Jangipur because of the control of Farakka barrage on the release of discharge in the downstream (the River Padma). Figure $2 b$ indicates the annual maximum discharge variation near Rajmahal and Jangipur. The graph shows annual maximum discharge is always high and it ranges from 20,000 to $80,000 \mathrm{~m}^{3} / \mathrm{s}$ near Jangipur (downstream of Farakka barrage) than Rajmahal (upstream of Farakka barrage). The annual maximum discharge ranges from 20,000 to $60,000 \mathrm{~m}^{3} / \mathrm{s}$ near Rajmahal. The higher values in annual maximum discharge near Jangipur is probably as a result of the extra water release from the barrage during the strong monsoon flow. However, it can be said that the barrage has enough control on the flow of water that affects the channel hydrology as well as the morphology of its immediate up and downstream.

\section{Hydrology controlled by seasonality and Farakka barrage}

Figure 3 displays the seasonal changes in the river water coverage in the up-stream of the barrage. Figure 3(A) stands for monsoon season whereas (B) represents the non-monsoon season. In case of the monsoon season
A

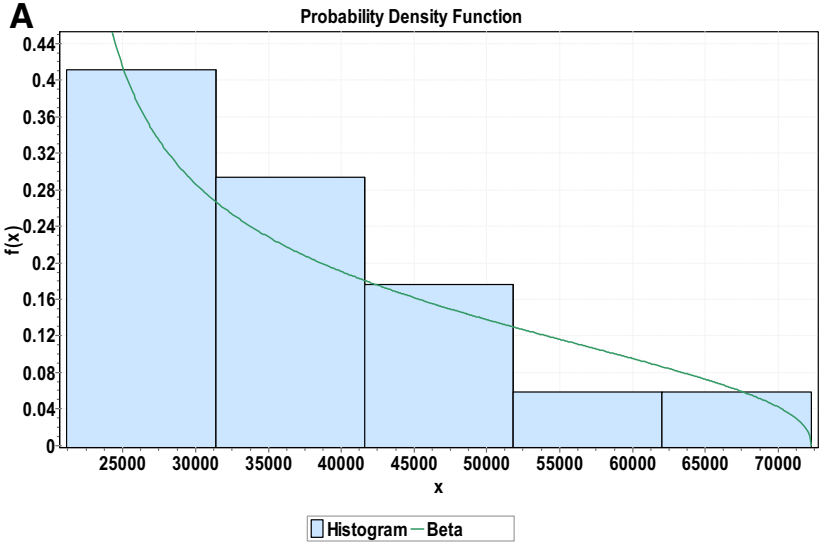

B

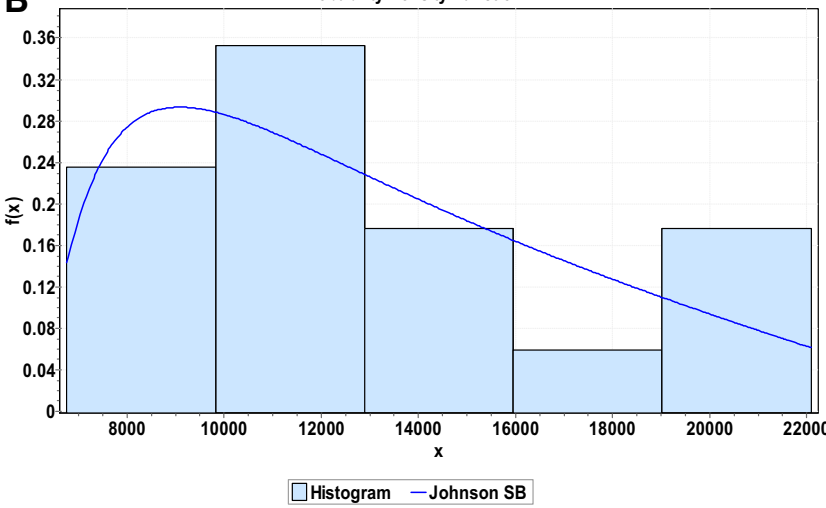

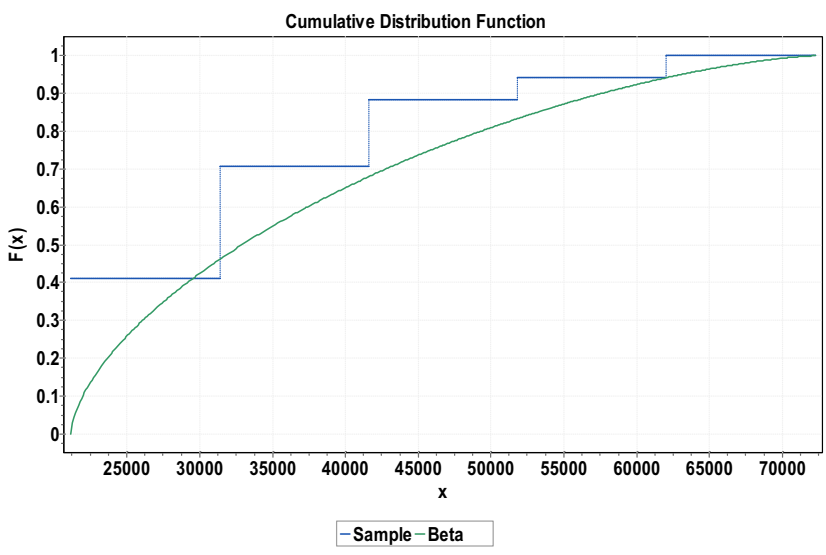

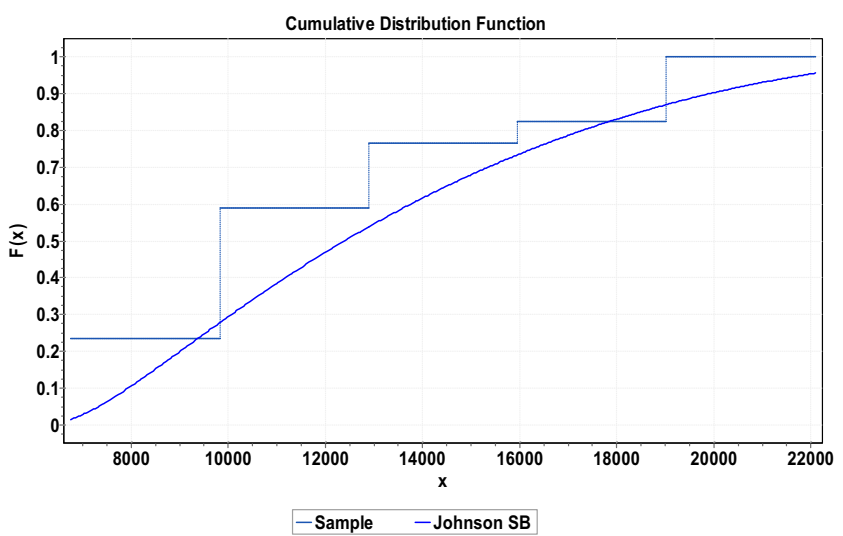

Fig. 6 Probability density function and cumulative distribution function of maximum daily discharge a and discharge volume or flood volume b of Rajmahal station 
(A) water cover area of the river is greater in comparison to the non-monsoon season (B). The Fig. 3A1 and B1 exhibits a channel bar near Rajmahal station. It shows the size of the bar is as larger in the non-monsoon season. In the same way A2 and B2 exhibits another channel bar just immediate to up-stream of the barrage and the scenario is alike with the previous one. The size of the two bars is larger in the non-monsoon season because of the low discharge flow during the non-monsoon period in comparison to the monsoon season. Figure 4 displays another seasonal change of the river water coverage in the down-stream of the barrage. The size of the channel bar, immediate to down-stream of the barrage (Fig. 4A1, B1) is much larger in the non-monsoon season image with than the monsoon season image. The size of another large bar, far downstream of the barrage is also relatively larger in the nonmonsoon image. Furthermore, the river in the down-stream of the barrage is narrower during the non-monsoon season in comparison to the down-stream (monsoon season) and the up-stream of the river in both the season.

The reason is probably the discharge regulation by Farakka barrage because the amount of discharge is so high that the barrage is compelled to release water to the down- stream during the monsoon season and the distribution of discharge in the up and down-stream remains in balance. But the barrage during the non-monsoon season stores the coming river discharge in the up-stream (because of low discharge inflow to the river in the non-monsoon season and to constant the flow of the Bhagirathi-Hughly River through the feeder canal) and is able to release less amount of discharge to the down-stream. Water cover area of the river in the up-stream of the barrage is more prominent than in the down-stream especially in the non-monsoon season image. This is due to the accumulation of discharge in the up-stream by the barrage.

Figure 5 shows the relations of seasonal discharge and runoff variability between Rajmahal and Jangipur stations during the period 1998-2014. In this figure, A and B represents mean monsoon and mean non-monsoon discharge whereas $\mathrm{C}$ and $\mathrm{D}$ represents mean monsoon and mean nonmonsoon runoff respectively. The relations of mean monsoon and mean non-monsoon discharge between these two stations indicate that the $\mathrm{R}^{2}$ is higher in monsoon season (0.4262) compared to the non-monsoon season (0.3271). The reduction of the value of $\mathrm{R}^{2}$ in case of the non-monsoon season in comparison to the monsoon season occurs
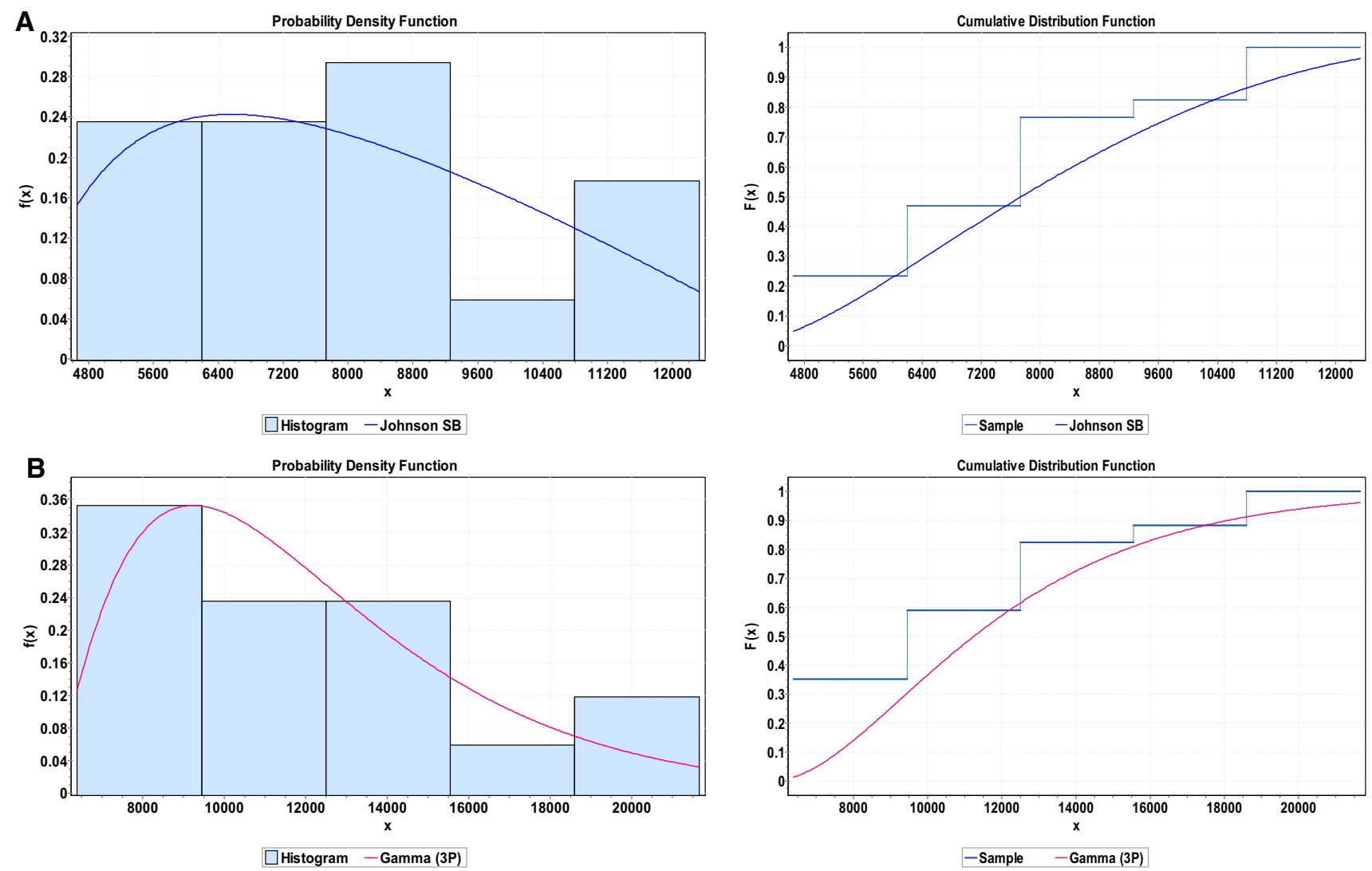

Fig. 7 Probability density function and cumulative distribution function of maximum daily discharge a and discharge volume or flood volume b of Jangipur station 
simply because of the control of Farakka barrage on the discharge release. The relationship of seasonal runoff between the two stations indicates that the fluctuation of $\mathrm{R}^{2}$ value in monsoon (C) and non-monsoon season (D) is largely controlled by Farakka barrage. Furthermore, the monsoon season discharge is influenced more by the barrage in comparison to the monsoon season runoff. However, it is clear that the channel flow is significantly controlled by the barrage, the seasonality and seasonal variability of discharge as well as runoff. Hence, it can be said that the channel morphology changes more effectively during the monsoon season than the other months of a year.

\section{Flood scenarios-simple Gumbel analysis}

The flood severity has a paramount role in the channel hydrology and planform dynamics as well as on the floodplain environment. Moreover, it adversely affects the riverine human habitats. The study reach of the River Ganga is highly flood affected (Singh 2007). The flood characteristics of the study reach are mostly controlled by monsoon rainfall and pre and post cyclonic monsoon burst. The flood events in the downstream of Farakka barrage is controlled by the barrage along with the above mentioned factors. In order to understand the flood scenario two set of data has been used: one is maximum annual discharge (as the proxy of peak discharge) and discharge volume of Rajmahal station (up-stream of Farakka barrage) and second is maximum annual discharge (as the proxy of peak discharge) and discharge volume of Jangipur station (down-stream of Farakka barrage). The detail of data issue regarding flood has been discussed in the data used section of the methodology (3.1). The Gumbel method of flood frequency analysis has been applied to both the data sets
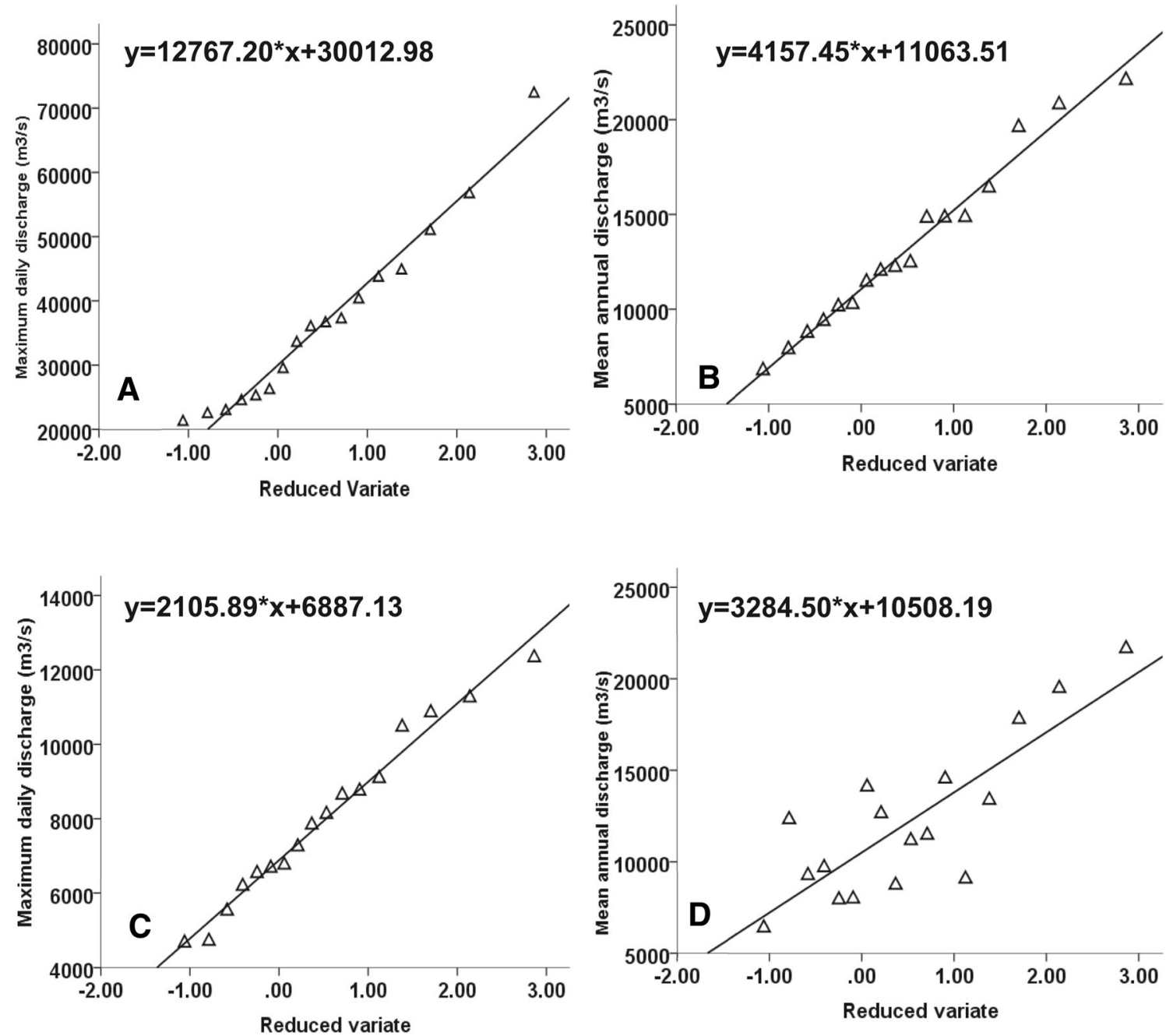

Fig. 8 Distribution of maximum daily discharge $\mathbf{a}, \mathbf{c}$ and discharge volume or flood volume $\mathbf{b}, \mathbf{d}$ of Rajmahal and Jangipur stations with respect to their reduced variate respectively 
Fig. 9 Return period of maximum daily discharge a, c and discharge volume or flood volume $\mathbf{b}, \mathbf{d}$ of Rajmahal and Jangipur at different values respectively
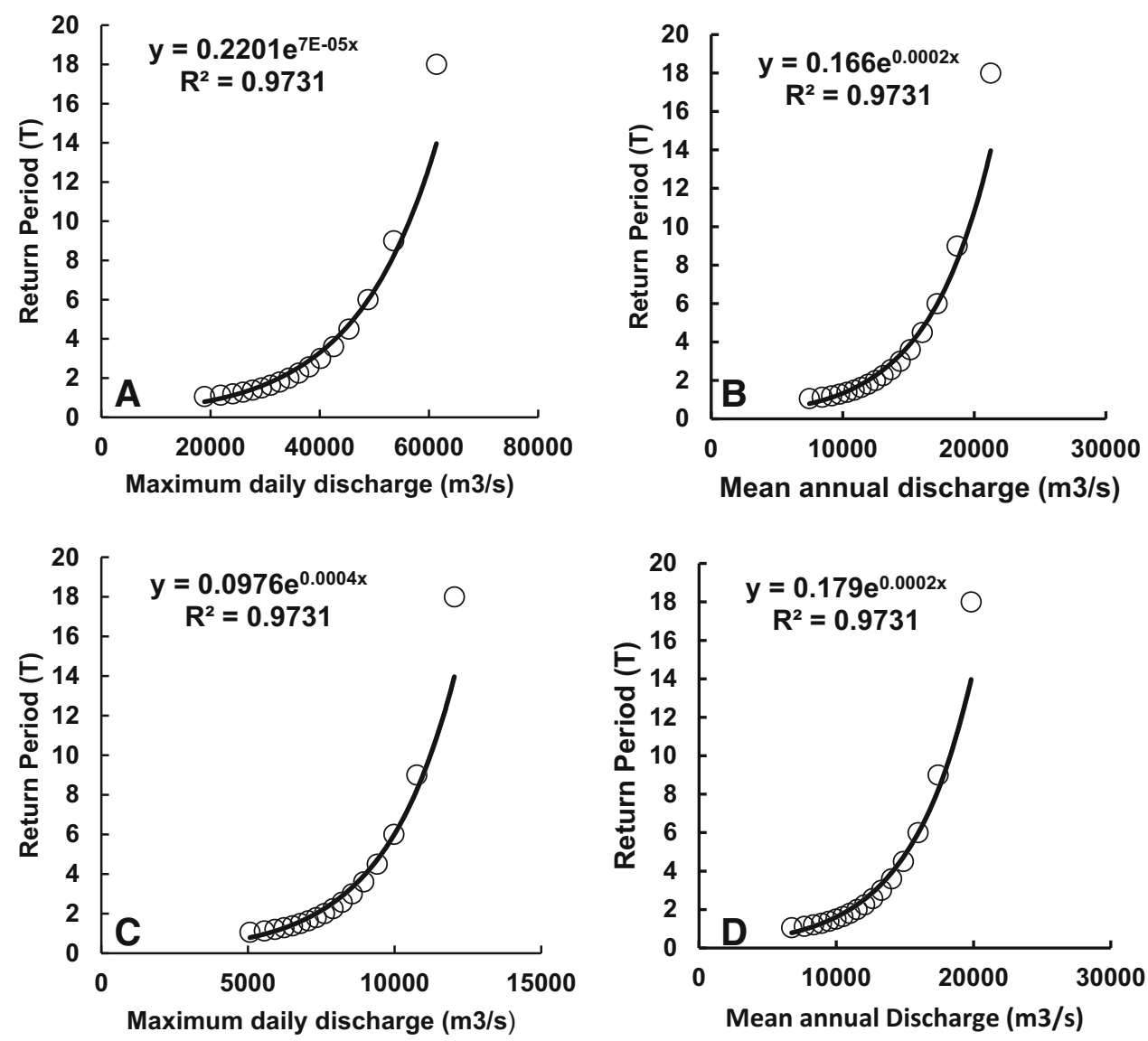

(maximum daily discharge and discharge volume or flood volume of the two stations). Figures 6 and 7 shows the probability density function and cumulative distribution function of the maximum daily discharge (A) and flood volume (B) of Rajmahal and Jangipur respectively. The data set has been transformed into normalization for the analysis and has been plotted against reduced variate (Fig. 8).

Figure 9 exhibits exponential changes of maximum daily discharge $\left(\mathrm{R}^{2}=0.9731\right)$ flood volume $\left(\mathrm{R}^{2}=0.9731\right)$ at Rajmahal station and maximum daily discharge $\left(\mathrm{R}^{2}=0.9731\right)$, flood volume $\left(\mathrm{R}^{2}=0.9731\right)$ at Jangipur station with the change of their return period (recurrence interval). All the parameters are well fitted with the exponential curve. Each of the graphs in the Fig. 9 indicates the highest return period of $\sim 20$ years which imply that the occurrence of the flood parameters is rareonce in the span of 20 years. The next highest return period is about 10 years. The magnitudes of maximum daily discharge and flood volume for Rajmahal are $\sim 50,000$ and $\sim 18,000 \mathrm{~m}^{3} / \mathrm{s}$ whereas the value of maximum daily discharge and flood volume for Jangipur are $\sim 12,000$ and $\sim 17,000 \mathrm{~m}^{3} / \mathrm{s}$ with 10 years recurrence interval which plays a crucial role in the changing river hydrology and the transformation and evolution of the channel as well as the adjoining recent floodplain structure. Though the magnitude of the parameters with 20 years recurrence interval is little higher than the 10 years recurrence interval, the 10 years interval is more crucial for the channel and adjoining floodplain dynamics as the 10 years event occurs twice in 20 years. The rest values of the two parameters of flood of the two stations have a regular but less intense impact (1-5 years recurrence interval) on the channel hydrology and planform dynamics. However, the analysis is fully based on satellite based data and the results would have been more accurate if access to recent discharge data of Farakka barrage was permissible.

\section{Conclusion}

The study is mainly based on satellite images and satellite based discharge data considering their limitations. This study tried to investigate the role of Farakka barrage on the channel hydrology modification and seasonal discharge variability in the up and down-stream of the barrage. The study reflects that particularly during the non-monsoon season the down-stream of the barrage is affected 
adversely. Moreover, the Jalangi River, a distributary of the Padma River, flowing to the south across West Bengal, is now a stagnant channel in terms of its flow and morphological processes because the zone of bifurcation is now filled by a point bar of the Padma River. The regularity of low discharge since the commission of Farakka barrage may be a key reason for the present condition of the Jalangi River along with the migration of the Padma River in the down-stream of the barrage which has also been triggered by the barrage regulated hydrology. However, further intensive investigation is required before one reaches any decision. However, it is to be noted that seasonality and the barrage both play a significant role in hydrology and planform morphology to the down-stream of the barrage i.e., the Padma River as well as the Bhagirathi-Hughly River and the immediate up-stream of the barrage.

Acknowledgements The first author would like to acknowledge the financial assistance received from the University Grants Commission (UGC), India. The author is also thankful to Tiyali Bose and Prasenjit Achariya for their help and suggestions.

\section{References}

Gupta N, Atkinson PA, Carling PA (2013) Decadal length changes in the fluvial planform of the River Ganga: braiding a mega-river to life with landsat archives. Remote Sensing Lett 4:1-9

Gupta N, Kleinhans MG, Addink EA, Atkinson PM, Carling PA (2014) One-dimentional modeling of a recent Ganga avulsion: assessing the potential effect of tectonic subsidence on a large river. Geomorphology 213:24-37
Mirza MQ (1997) Hydrological changes in the Ganges system in Bangladesh in the post-Farakka period. Hydrol Sci J 42(5):613-631

Pal R (2015) Fluvial planform dynamics and adjoining floodplain morphology: a study from the middle-lower part of the river Ganga, India. New Delhi: Unpublished M. Phil., dissertation, CSRD, JNU

Raghunath HM (2006) Hydrology: principles, analysis, design. New Age International Limited, Publishers, New Delhi

Rudra K (2010a) Banglar Nadikatha (Bengali). Sahitya Sanshad, Kolkata

Rudra K (2010b) Dynamics of the Ganga in West Bengal, India (1764-2007): implications for science policy interaction. Quatern Int 227:161-169

Singh R (1971) India: a regional geography. National Geographical Society of India, Varanasi

Singh IB (1987) Sedimentological history of quaternary deposits in gangetic plain. Indian J Earth Sci 14:272-282

Singh IB (2004) Late quaternary history of the Ganga plain. J Geol Soc India 64:431-454

Singh IB (2007) The Ganga River: geomorphology and management. In: Gupta A (ed) Large rivers. Wiley, London, pp 347-371

Singh M, Singh IB, Muller G (2007) Sediment characteristics and transportation dynamics of the Ganga River. Geomorphology 86:144-175

Sinha R, Friend PF (1994) River systems and their sediment flux, Indo-Gangetic plains, Northern Bihar, India. Sedimentology 41:825-845

Subramanya K (2013) Engineering hydrology. McGraw Hill Education (India) Private Limited, New Delhi

$\mathrm{Xu} \mathrm{H}$ (2006) Modification od normalized difference water index (NDWI) to enhance open water features in remotely sensed imagery. Int J Remote Sens 27(14):3025-3033

Yue S, Quarda T, Bobee B, Legendre P, Bruneau P (1999) The Gumbel mixed model for flood frequency analysis. J Hydrol 226(1-2):88-100 